\title{
MUDANÇA DE ESTRUTURA MORAICA DO LATIM AO PORTUGUÊS
}

\author{
Evellyne Patrícia Figueiredo de Sousa COSTA*
}

- RESUMO: Este estudo tem como objetivo investigar a evolução da estrutura moraica do latim ao português. A língua latina apresenta distinção quantitativa vocálica e consonantal: (i) sílabas leves, portadoras de uma mora (e.le.men.tum); (ii) sílabas pesadas, portadoras de

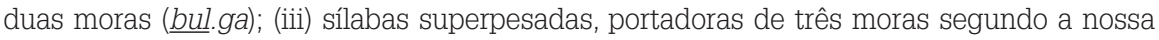
proposta (paul.lum). Diacronicamente, há a perda da distintividade quantitativa dentre as vogais e, na passagem às línguas neorromânicas, a estrutura moraica tem seus efeitos. Diante desse cenário e a partir dos pressupostos da Teoria Moraica de Hayes (1989), investigamos os efeitos dessa mudança através de processos fonológicos envolvidos, tais como ditongação e monotongação. A Teoria Moraica busca caracterizar de que modo as línguas atribuem estrutura moraica e que princípios atuam nessas línguas. Hayes (1989) define mora como uma unidade de peso do tier prosódico que caracteriza o contraste entre sílabas longas e breves, além de contar como uma posição fonológica (segmento longo é representado como duplamente ligado). Propomos que as escolhas feitas pela língua portuguesa, tais como ditongação e monotongação, para lidar com a estrutura moraica latina já estão disponíveis em latim vulgar e que princípios como Stray Erasure e Parasitic Delinking, relacionados com Licenciamento Prosódico atuam na referida mudança.

- PALAVRAS-CHAVE: Mudança. Latim. Estrutura moraica. Moras. Português.

\section{Introdução}

A sílaba em latim é geralmente caracterizada, por estudos mais tradicionais, como uma sequência de sons (COUTINHO, 1958; FARIA, 1955; SILVA NETO, 1957; LAUSBERG, 1963). Além disso, a simplificação de vogais longas ou de consoantes geminadas e o apagamento de consoantes pós-vocálicas são processos descritos como processos separados e sem se fazer menção aos efeitos desses fenômenos nas línguas românicas.

Diante desse panorama, e do pressuposto de que as referidas mudanças dizem respeito à mora, o presente artigo trata dos efeitos da mudança de estrutura moraica do latim ao português sob a ótica da Fonologia das Moras (HAYES, 1989), mais precisamente da perda da quantidade vocálica (vogais longas) e da

* UFSM - Universidade Federal de Santa Maria. Centro de Artes e Letras - Departamento de Letras Clássicas e Linguística - RS - Brasil. 97105900 - evellynepatricia@hotmail.com 
quantidade consonantal (consoantes geminadas e pós-vocálicas), interpretadas como um único processo, qual seja, mudança de estrutura moraica.

\section{Teoria das Moras}

Hayes (1989) assevera que o tier prosódico é constituído por unidades de peso, isto é, por moras. A mora representa duas questões importantes nessa teoria: (i) o contraste entre sílabas pesadas ( $\mu \mu)$, que têm duas moras, e sílabas leves ( $\mu$ ), que têm uma mora; (ii) a forma de representação de uma posição fonológica por meio da mora, ou seja, um segmento longo é representado como duplamente associado, ao passo que um segmento simples é representado através de uma única linha de associação. A teoria das moras, portanto, não é uma teoria segmental, não há processos fonológicos que contam segmentos, mas que contam moras ou sílabas. A sílaba, dentro dessa abordagem, não apresenta onset e rima, somente moras.

Algumas línguas permitem sílabas pesadas, mas não permitem que a vogal ocupe duas moras, como o português. De outra maneira, uma língua pode ter sílaba pesada composta por vogal longa e não contar sílabas travadas por consoante como pesadas.

O latim, por exemplo, possui vogais longas e vogais curtas, assim como sílabas pesadas (CVV e CVC) e sílabas leves (CV), ao passo que o português possui somente vogais curtas. Em latim, várias regras e restrições identificam CVC como sílaba pesada, tais como atribuição de acento, métrica e encurtamento iâmbico. Já para o lardil, apenas CVV é pesada, CVC e CV são sílabas leves. Processos de truncamento, aumento e reduplicação são fenômenos que identificam CVC como sílaba leve nessa língua. Percebemos, pois, que a estrutura moraica é variável entre as línguas. A mora, então, passa a ser objeto de pesquisa de muitos autores que se preocupam com o peso e a quantidade silábica, como Pulleyblank (1994), Lahiri, Riad e Jacobs (1999), Morén (1999), Cohn (2003), Magalhães (2004), Oostendorp (2005), Elfner (2006), Brennan (2008), dentre outros.

As questões mais importantes para a Teoria das Moras são as seguintes: (i) como as línguas atribuem estrutura mórica?; (ii) que estrutura moraica é contrastiva fonologicamente? Acrescentamos, nesse momento, uma indagação: Quais são os efeitos da mudança de estrutura moraica diacronicamente?

Em línguas nas quais há uma distinção quantitativa, vogais longas possuem duas moras e vogais curtas, uma mora, como nos exemplos (1) e (2) respectivamente. As consoantes simples são representadas, na subjacência, sem status moraico, ou seja, a esses elementos não são atribuídas moras, da mesma maneira, o glide não possui mora, como vemos nos exemplos (3) e (4). 
(1) Vogal curta /i/

$$
\prod_{\mathrm{i}}^{\mu=/ \mathrm{i} /}
$$

(2) Vogal longa /i:/

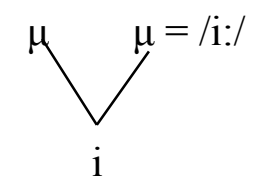

(3) Consoante simples

$$
=/ \mathrm{n} /
$$

$\mathrm{n}$

(4) Glide

$$
=/ \mathrm{y} /
$$

i

As geminadas recebem uma mora na subjacência, como vemos em (5), para distingui-las das consoantes simples, exemplo (6).

(5) Geminadas

$$
\mu=/ \mathrm{n}: /
$$

$\mathrm{n}$ 
(6) Consoantes simples

$$
=/ \mathrm{n} /
$$

$\mathrm{n}$

A consoante simples, quando pós-vocálica, recebe mora por Weight by position: "coda consonants are given a mora when they are adjoined to the syllable"1 (é atribuída uma mora às consoantes em coda quando adjungidas à sílaba). Weight by position é uma regra específica de língua que se aplica nas línguas para as quais CVC é pesada, em línguas nas quais CVC é leve, a regra não se aplica. A representação está em (7).

(7) Weight by position

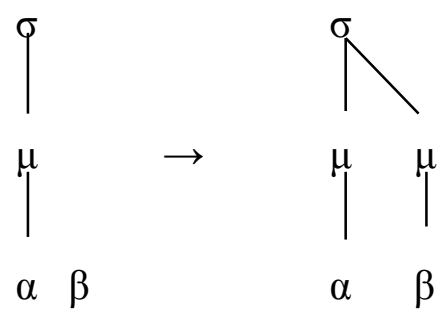

Se, em uma língua, apenas um grupo de consoantes é capaz de dar peso à sílaba quando em posição de coda, isso deve ser informado em $\beta$. Em latim, língua na qual CVC é uma sílaba pesada, Weight by position atribui uma mora à consoante na coda silábica, em lardil, por exemplo, não há uma regra desse tipo e a consoante pós-vocálica é associada à mora precedente. Weight by position é referido por muitos estudiosos a partir da proposta de Hayes (1989), tais como Gordon (1999), Rosenthal e Hulst (1999), dentre outros.

Segundo Hayes (1989), a silabificação consiste, primeiramente, na seleção de segmentos moraicos, respeitando a sonoridade, para ocupar o núcleo silábico, exemplo (8), após esse passo, a sílaba é atribuída, como em (9).

(8) Formas subjacentes
a)
b) $\mu$

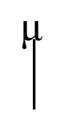
c) $\mu \mu$

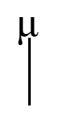
d) $\quad \mu \mu \mu$
a $\mathrm{t}$ a
a p t a
a pt a
a $\mathrm{t}$ a

Hayes (1989, p.258). 
(9) Atribuição de $\sigma$

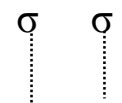

a)<smiles>[TlH][TlH]</smiles>

b)<smiles>C[AlH]</smiles>

a $\mathrm{p} \mathrm{t}$ a

$$
\sigma
$$<smiles>OC1CCO1</smiles>

c)

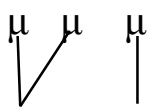

a $\mathrm{pt} \mathrm{a}$

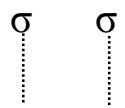

d)

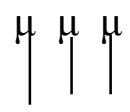

a $\mathrm{t}$ a

A partir disso, ainda respeitando a sonoridade, as consoantes são adjungidas ao onset do nó da sílaba, como em (10).

(10) Adjunção de consoantes pré-vocálicas

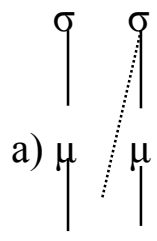

a $\mathrm{t}$ a b)

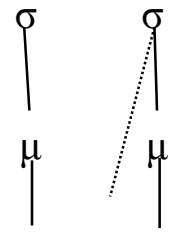

a $\mathrm{p} \mathrm{t}$ a c)

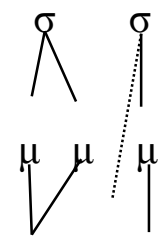

a $\mathrm{pt} \mathrm{a}$ d)

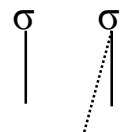

a $\mathrm{t} a$

As consoantes pós-vocálicas são associadas via Weight by Position, como (11) representa. A geminada possui uma mora na subjacência, por isso fica associada à sílaba precedente e à sílaba seguinte, exemplo (12d). Consoantes pós-vocálicas em sílabas duplamente travadas são adjungidas através de Adjunção de segmentos restantes, sem conferir peso à sílaba, exemplo (12c).

(11) Adjunção por Weight by Position

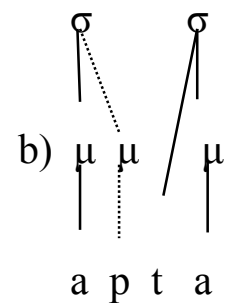


(12) Adjunção de segmentos restantes

c)

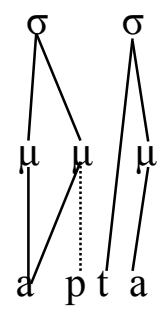

d)

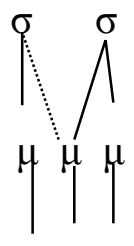

a $\mathrm{t}$ a

\section{$\left[\begin{array}{lll}\text { [ata }] & {[\mathrm{apta}]} & {[\mathrm{a}: \mathrm{pta}]}\end{array}\right.$}

A preocupação com relação a quais segmentos podem portar mora e de que maneira se dá a atribuição de estrutura moraica está presente em muitos trabalhos que se reportam a vogais longas e geminadas em contraposição a vogais curtas e consoante simples em diferentes línguas, tais como Chung (1997), Hume, Muller e Engelenhoven (1997), Morén (1999), Arvaniti (2001), Curtis (2003), Gore (2003), Brown (2003), McCray (2006), Onzi (2007), Gordon et al. (2008), Odden (2010).

Como o objetivo deste trabalho é dar conta da resolução da perda de quantidade vocálica e de quantidade consonantal na passagem do latim ao português como um único processo, qual seja, mudança de estrutura moraica, o alongamento compensatório se mostra um processo de conservação de mora, assim como a geminação consonantal e a ditongação. Autores como Gasiorowski (1993), Kavitskaya (2002), Lunden (2006) e Shaw (2008) tratam de alongamento compensatório de acordo com os pressupostos de Hayes (1989).²

Alongamento compensatório é definido por Hayes (1989) como alongamento de um segmento engatilhado pelo apagamento ou encurtamento de um segmento vizinho. O autor trata dos seguintes tipos de alongamento compensatório: (i) alongamento "double flop"; (ii) alongamento por perda vocálica; (iii) alongamento por formação de glide; (iv) alongamento managerial. Todos esses fenômenos se caracterizam por serem processos de conservação de mora. Vejamos um exemplo de alongamento compensatório por perda consonantal em (13), no qual a vogal é alongada para compensar o apagamento de /s/.

\footnotetext{
2 Muitos autores, como os que citamos aqui, tratam das questões discutidas por Hayes (1989) na perspectiva da Teoria da Otimidade. Entretanto, esse não é o nosso objetivo neste trabalho. Hayes et al (2011) e Goldsmith () tratam de fenômenos relativos ao peso e a processos fonológicos a partir de teorias outras que não a TO.
} 
(13) Alongamento compensatório por perda consonantal em latim

\begin{tabular}{|l|l|l|}
\hline *kasnus $^{4}$ & ka:nus & Cinza \\
\hline *kosmis & ko:mis & Afável \\
\hline *fideslia & fide:lia & Pote \\
\hline
\end{tabular}

O problema reside no fato de /s/ inicial apagar sem engatilhar alongamento vocálico, em latim, como podemos ver em (14). Segundo Hayes (1989), a Teoria das moras dá tratamento adequado ao apagamento de /s/ em ambas as situações em latim: sílabas do tipo CVC em latim são pesadas, por conta disso, /s/ em posição de coda é portador de mora, ao passo que /s/ em posição de onset não possui mora.

(14) Perda consonantal sem alongamento compensatório

\begin{tabular}{|c|c|c|}
\hline *smereo & mereo & "eu mereço" \\
\hline$*_{\text {snurus }}$ & nurus & "nora" \\
\hline *slu:bricus & lubricus & "escorregadio" \\
\hline
\end{tabular}

Quando ocorre o apagamento, a mora da consoante elidida permanece flutuante e é associada à vogal precedente, resultando um segmento vocálico longo, exemplo (15). Como /s/ inicial não carrega mora, o apagamento desse elemento não deixa mora desassociada e não provoca alongamento compensatório.

(15) Alongamento compensatório por perda consonantal

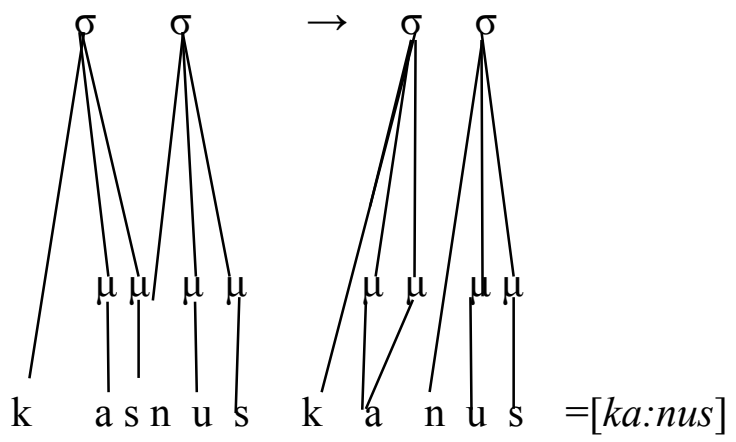

Entretanto, Hayes (1989) observa que o alongamento vocálico compensatório não é geral, pois há línguas nas quais o mesmo não se aplica, razão pela qual o autor não o considera um fenômeno exclusivo das moras, mas também da sílaba.

3 O asterisco identifica formas ainda não atestadas na língua. 
Algumas línguas não alongam a vogal, mas alongam a consoante à esquerda ou à direita, criando uma geminada. De que maneira dar o status universal a um comportamento tão variável das línguas?

Hayes (1989) argumenta que, se o alongamento compensatório fizer parte dos Princípios Universais de Silabificação, o caráter universal e a variabilidade são garantidos. Os Princípios Universais de Silabificação são os seguintes: (i) Licenciamento Prosódico: os elementos prosódicos de um nível mais alto, como as moras, devem estar associados a constituintes mais altos na hierarquia prosódica; (ii) Stray Erasure: elementos que não são associados, são apagados no final da derivação; (iii) Parasitic Delinking: toda a estrutura da sílaba deve ser deletada quando a sílaba não contiver um elemento nuclear. Os mecanismos de alongamento estão inseridos na silabificação se licenciarem moras vazias. Dessa maneira, o universal e o variável fazem parte da teoria.

O peso silábico é tratado como uma oposição binária, isto é, $\mu \mu$ é o máximo de moras que uma sílaba pode carregar. Mesmo que haja consoantes adjungidas a sílabas do tipo CVC e CVV, essas consoantes são agregadas à última mora e não dão mais peso à sílaba de acordo com a teoria.

Essa limitação de duas moras faz predições interessantes, por exemplo, o apagamento de uma consoante em uma sílaba duplamente travada não engatilha alongamento compensatório. Entretanto, Hayes (1989) apresenta alguns argumentos que comprovariam a existência de sílabas trimoraicas em algumas línguas. A manutenção da bimoraicidade em detrimento da trimoraicidade será objeto de discussão desse trabalho mais adiante.

O processo de alongamento compensatório se aplica em sílabas duplamente travadas em protogermânico. Nessa língua, o apagamento de uma consoante [n], antes de [x], provoca o alongamento em sílabas duplamente travadas, mesmo que sejam não finais: * ${ }^{*}$ anxta $\rightarrow{ }^{*} \theta$ a:xta. Essa mudança não pode ser explicada sem que consideremos a sílaba em questão trimoraica.

O segundo argumento é baseado no fato de distinções de peso silábico referidas por algumas regras de acento levarem em conta sílabas trimoraicas. É o que ocorre em sílabas superpesadas em Hindi (CVVC, CVCC). Essas sílabas são tratadas de maneira diferente das sílabas pesadas (CVV, CVC). Nessa língua, as sílabas superpesadas comportam-se como sequências de sílaba pesada + sílaba leve em qualquer lugar da palavra.

A existência de sílabas trimoraicas ainda é sustentada por um terceiro argumento: algumas línguas apresentam uma distinção de duração vocálica tripartida (/V/ - /V:/ - /V: :). Hayes (1989) assevera que alguns dialetos do alemão possuem essa distinção. Historicamente, segundo o autor, essa distinção teria se originado no processo de alongamento compensatório por conta do apagamento 
da vogal seguinte. Percebemos que as sílabas trimoraicas são resultado de alguma operação morfológica ou fonológica. O latim não está inserido nas situações apontadas por Hayes (1989), que também não aplica a teoria a dados diacrônicos.

A análise que será apresentada da evolução da quantidade vocálica e consonantal, que diz respeito à estrutura moraica do latim ao português, tomará os pressupostos da Fonologia das Moras. ${ }^{4}$ Questões como variação da estrutura moraica em latim, conservação e perda de mora, efeitos de Stray Erasure, Parasitic Delinking e Weigth by Position serão discutidas.

\section{Efeitos da mudança de estrutura moraica do latim ao português}

Este estudo se concentra na evolução da estrutura moraica, especialmente das vogais longas e das consoantes geminadas, bem como das consoantes pós-pico do latim clássico e de seu reflexo em português. É sabido que o latim clássico apresenta uma distinção fonológica entre vogais longas e vogais curtas e entre consoantes simples e consoantes geminadas. Todavia, na variedade latim vulgar, a distinção efetiva entre as vogais longas e curtas começa a enfraquecer, apresentando, desde então, variação entre a consoante dupla e sua correspondente simplificada e entre a vogal longa e vogal curta.

A distinção da quantidade vocálica se perde na passagem do latim às línguas românicas com resultados diferentes nas línguas derivadas. ${ }^{5}$ Com relação à quantidade consonantal, das dez línguas que compõem a România - português, espanhol, francês, italiano, romeno, sardo, provençal, catalão, dálmata e retoromano (RENZI, 1982) -, apenas o italiano e o sardo preservam as consoantes geminadas, ao passo que as demais línguas as simplificaram.

Tomando como pressuposto Hayes (1989), assumimos que a evolução da quantidade vocálica e da quantidade consonantal, comumente tratados como fenômenos separados, pode ser explicada via Fonologia das Moras como um só fenômeno. Interessa-nos, pois, explicar a mudança da estrutura moraica na passagem do latim - língua de sistema quantitativo - ao português - língua advinda do sistema itálico ou vulgar (LAUSBERG, 1963).

4 Lee (2003) discute a relação entre síncope e o padrão do acento em PB a partir da Teoria Métrica de Hayes (1995).

5 Para Lee (1995), o português não seria sensível ao peso silábico. Em contrapartida, Massini-Cagliari (1999) afirma que há vogais bimoraicas em português em exemplos como pomar e cafeC. De acordo com a autora, a vogal do núcleo ocuparia duas moras. Essa visão difere dos estudos de Bisol (1992): atribua um * à sílaba pesada final. Em cafeC, a consoante abstrata confere peso à última sílaba. Partimos do pressuposto de que não há vogais bimoraicas em português, mas que há efeitos da estrutura moraica do latim nessa língua. 
Com base no modelo de Hayes (1989), passamos a caracterizar a atribuição da estrutura moraica do latim de (17) a (118) em termos de três camadas: sílaba $(\sigma)$; mora $(\mu)$; segmentos.

O elemento mais sonoro, a vogal, recebe uma mora que vai ser dominada pelo nó da sílaba e a consoante é associada ao nó da sílaba como onset, como vemos em (16).

(16) elementum (elemento)

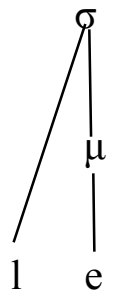

Em latim, tanto a vogal longa, quanto a consoante em coda contribuem para o peso silábico, como veremos a seguir. No exemplo abaixo, as vogais, elementos mais sonoros, recebem mora subjacentemente e a consoante pré-pico é adjungida, constituindo-se a estrutura silábica, como podemos perceber em (17).

(17) $\underline{\text { dō }}$ (dou)

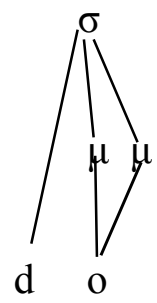

Em latim, a consoante que fecha a sílaba contribui para o peso. De acordo com a teoria, essa consoante porta mora via Weigth by Position, como mostra (18), pois, diferentemente das vogais, nem todas as consoantes são portadoras de mora, mas somente aquelas que se situam à direita do pico.

(18) bulga (bolsa)

$\sigma$

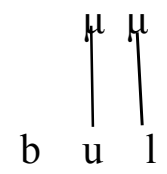


No exemplo (18), a mora é atribuída à vogal, formando a sílaba. A consoante pré-vocálica é associada ao nó da sílaba, sem contribuir para o peso, e a consoante pós-vocálica é adjungida via Weigth by Position, isto é, ocupa uma posição moraica, resultando em uma sílaba bimoraica.

Hayes (1989) defende a ideia de que a sílaba é maximamente binária, não importando quantas consoantes sejam associadas a sílabas CVV ou CVC. Entretanto o autor afirma que sílabas trimoraicas podem ocorrer em situações específicas, como as que seguem: (i) CL ${ }^{6}$ não é bloqueado em sílabas duplamente travadas (protogermânico); (ii) algumas línguas fazem referência a regras de acento que requerem sílabas trimoraicas (híndi); (iii) algumas línguas apresentam gradiência de distinção vocálica - /V/, /V:/, /V::/ (dialetos germânicos); (iv) em alguns casos, a métrica quantitativa identifica a trimoraicidade (persa). ${ }^{7}$ A discussão sobre o caráter binário ou não da estrutura moraica das sílabas não é ponto pacíico, a passagem que segue se detém nesse aspecto.

Os monossílabos spēs (esperança) e crās (amanhã) poderiam ser um contraargumento à ideia de que as sílabas sejam maximamente bimoraicas, pois duas moras antecedem a consoante, ou seja, temos uma sequência de vogais longas seguidas de consoantes simples em coda. Harris (1983), em situação semelhante, para o espanhol, afirma que o /s/ é associado via Regra de adjunção a estruturas silábicas prontas. Hayes (1989) estende esse procedimento a qualquer consoante que extrapole a estrutura binária. A isso, o autor chama de Regra de Adjunção de Elementos Restantes, como exemplificamos em (19).

(19) pēs (pé)

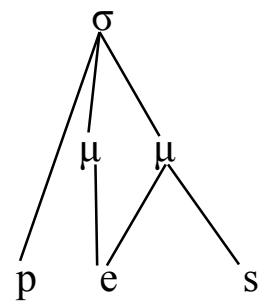

Em latim, no entanto, há sílabas compostas por ditongo seguido de geminada e sílabas compostas por vogal longa seguida de geminada. Nesse caso, a questão da sílaba trimoraica parece ressurgir.

\footnotetext{
6 Alongamento compensatório.

7 Cf. HAYES (1989).
} 
(20) paullum (um pouco)

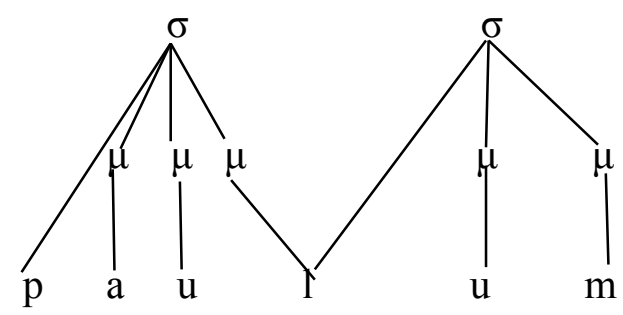

(21) penna (pena)

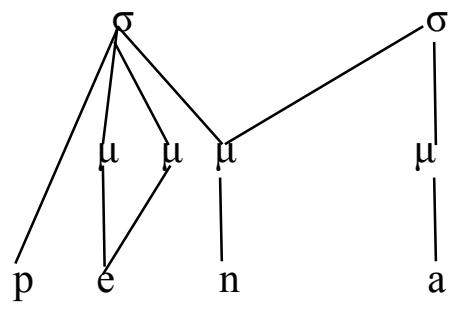

Nos exemplos (20) e (21), as vogais longas recebem duas moras, assim como os ditongos seguidos de geminada da qual uma folha constitui a terceira mora da sílaba e a outra constitui o onset da sílaba seguinte. A estrutura trimoraica que faz parte do sistema do latim clássico não é uma estrutura derivada como depreendemos das formas que seguem: vìllica, vīllico, mīlle, mīllia, stēlliger, stēmma, stēllo, stēllaris, paullo, paullus.

Os argumentos para sustentar essa afirmação são os seguintes: (i) a geminada é um elemento ao qual é atribuída uma mora na subjacência, por conseguinte, ao ser acrescentada a uma estrutura bimoraica, cria uma estrutura trimoraica; (ii) a variação encontrada em latim vulgar tem como característica reduzir a estrutura trimoraica do latim clássico a bimoraica através da redução da vogal longa ou da simplificação da geminada: pēna pěnna. A sílaba trimoraica, pois, converte-se em bimoraica.

A estrutura formada por vogal longa + geminada e ditongo + geminada entra em variação em latim vulgar. A sentença n ${ }^{\circ} 94$ do Appendix Probi ${ }^{8}$ registra "Süppellex non sūperlex", que os gramáticos latinos classificavam como "erro" em virtude da dificuldade na pronúncia de uma sequência na qual se encontrava uma vogal longa seguida de geminada. Esse tratamento diferente da estrutura

8 Appendix Probi é um glossário anônimo cujo objetivo é o de corrigir "erros" de pronúncia do latim falado. (APPENDIX..., 2011). 
complexa é, geralmente, reservado aos falantes da variedade mais popular da língua.

Nessa linha de pensamento, o processo diacrônico de mudança transformou uma estrutura trimoraica em uma estrutura bimoraica através da redução da vogal ou da simplificação da geminada, ou seja, via perda de mora. A variação entre vogal longa e consoante geminada, muito comum em latim vulgar, já ocorria em latim clássico, como podemos depreender dos seguintes registros dicionarizados (TORRINHA [1942?]): paulo ou paullo (pouco); paullus ou paulus (Paulo); pūpus ou puppus (pupila); sollers melhor que sōlers (hábil); succo ou sūco (usurário); succus ou melhor sūcus (suco); suggilatus ou sūgilatus (desacreditado); suggilo ou melhor sūgilo (pisar); vēlumen ou vellumen (faixa de lã); villlica ou vīlica (caseira); villlico ou vīlico (caseiro). Diante da variação entre vogal longa e consoante geminada, o dicionário de latim clássico aponta que algumas formas eram tidas como de maior prestígio: sŏllers melhor que sōlers; succus melhor sūcus; suggilo melhor sügillo. Em (22), representamos o registro no 94 do Appendix Probi.

(22) Forma clássica [su:ppeleks] (mobiliário)

$a^{\prime}$
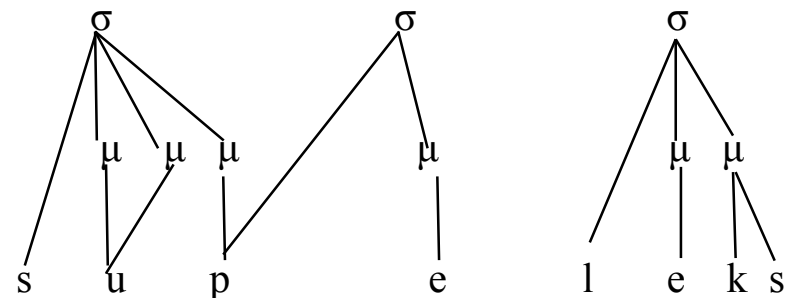

Na perspectiva defendida pelo presente trabalho, (22a") representa a desassociação que deixa a mora flutuante que, por não ser associada a nenhum elemento, é elidida por Stray Erasure, formando-se uma sílaba bimoraica.

(22) a"

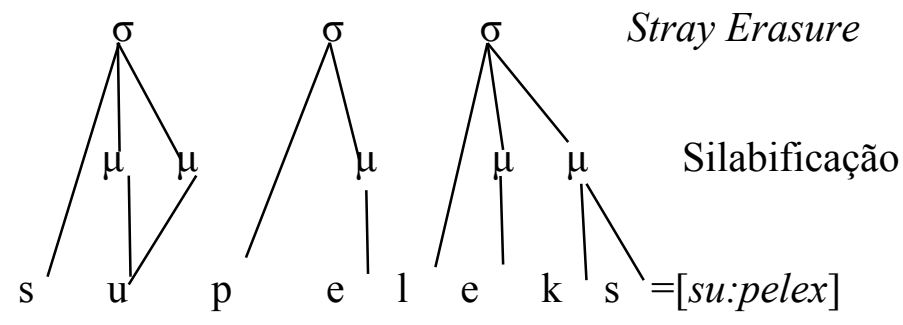


O exemplo (22b") descreve uma alternativa de simplificação da estrutura trimoraica em latim vulgar através da redução da vogal longa e da manutenção da geminada, emergindo mais uma vez a bimoraicidade.

(22) Forma clássica [su:ppeleks]

b'

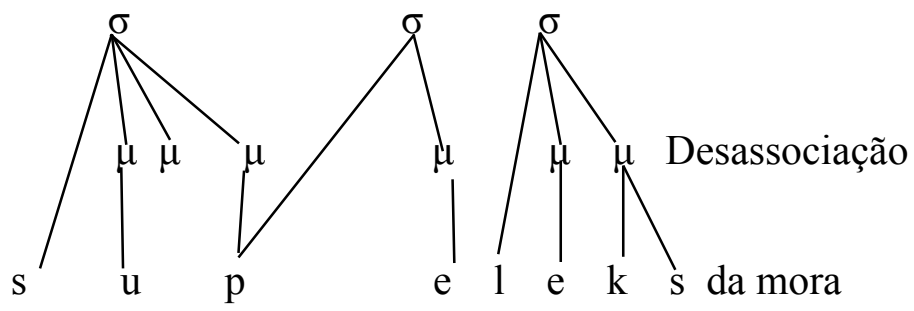

Diferentemente de (22a), a mora desassociada em (23b) é a mora da vogal que será elidida por Stray Erasure como mostra a representação abaixo.

b"
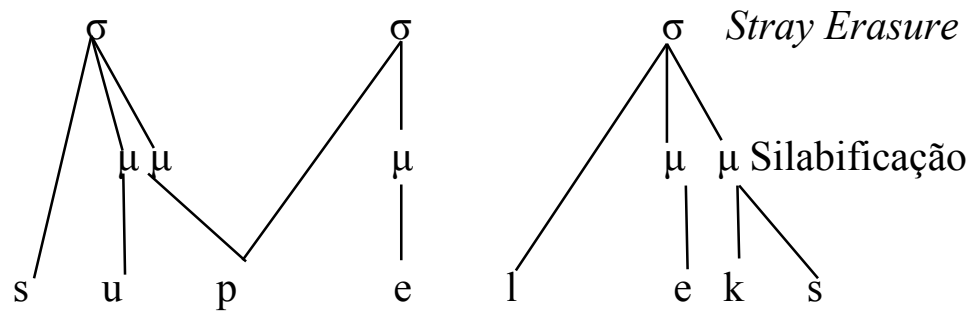

\section{$=[$ suppeleks $]$}

Há sílabas em latim formadas por ditongo mais consoantes simples, tais como auctor (autor) e auctoritas (autoridade). Tais estruturas também entrariam em variação em latim vulgar segundo os registros $\mathrm{n}^{\circ} 154$ auctor non autor e $\mathrm{n}^{\circ}$ 155 auctoritas non autoritas do Appendix Probi. Na verdade, a consoante simples que é adjungida à estrutura bimoraica não confere peso à sílaba, pois, de acordo com Hayes (1989), quando a bimoraicidade está preenchida, a consoante póspico é agregada à sílaba através da regra de Adjunção de Segmentos Restantes, motivo pelo qual o seu apagamento não ocasiona alongamento compensatório, como podemos ver em (23). 
(23) forma clássica [auktor] (autor)
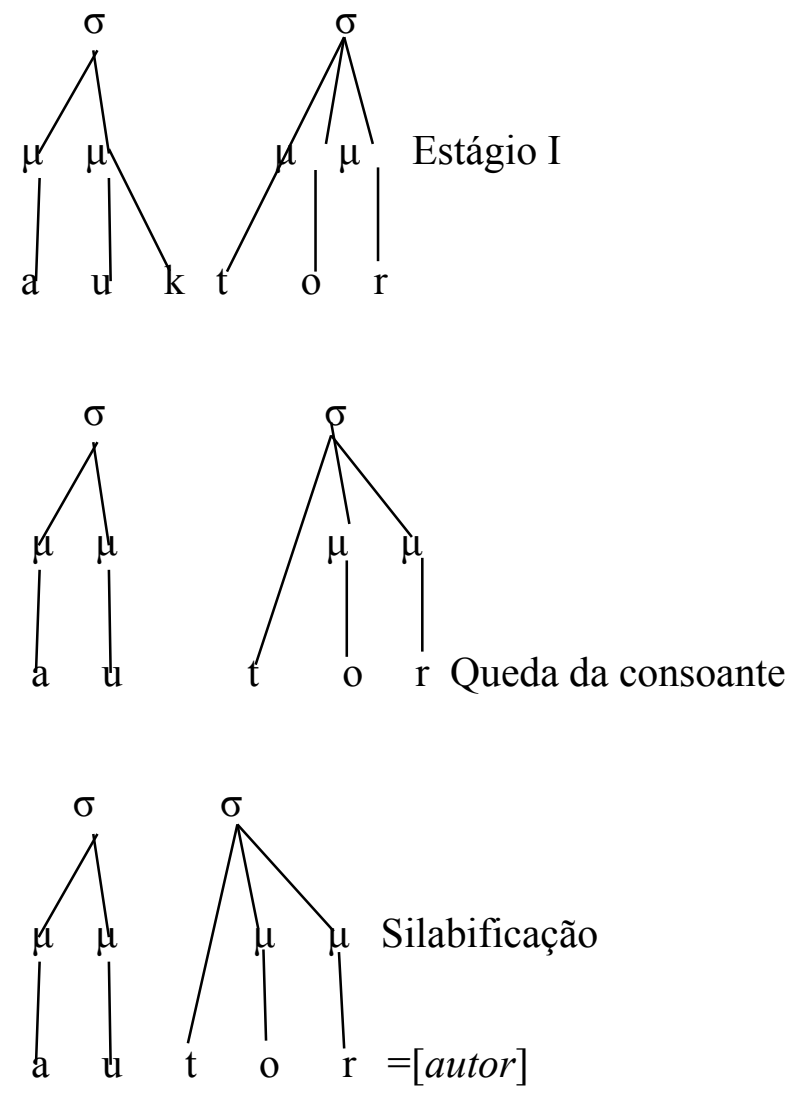

Como a consoante alvo de apagamento não porta mora, pois foi associada via Adjunção de segmentos restantes, não há modificação quanto à estrutura moraica nessas situações.

Em contrapartida, o registro ${ }^{\circ} 22$ do Appendix Probi exemplifica um caso de redução de ditongo: aquaeductus non aquiductus. O ditongoae é reduzido para /i/ quando forma um composto, assim como no registro n 159: terrae motus non terrimotus (terremoto). 
(24) forma clássica [akuaiduktus] (aqueduto)
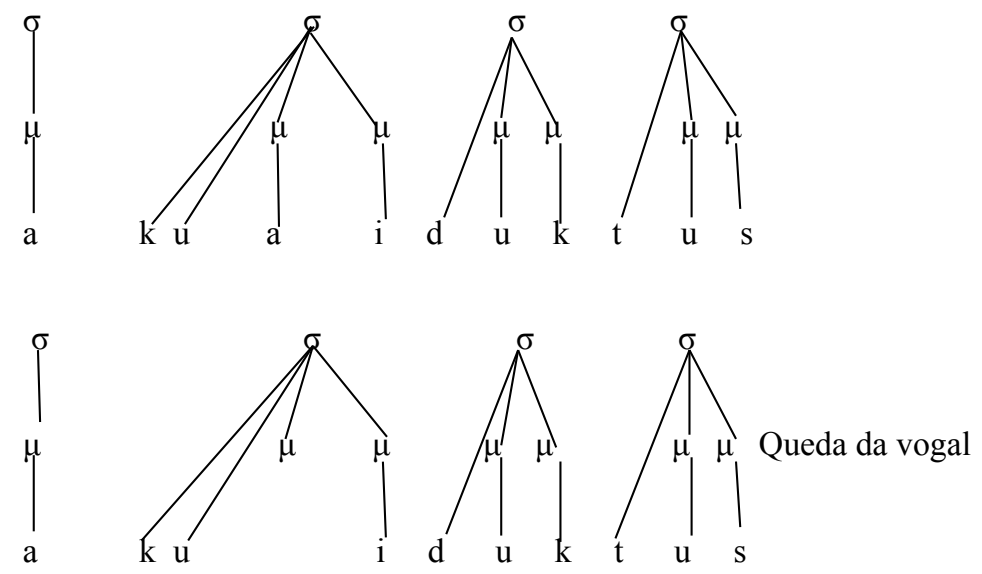

da

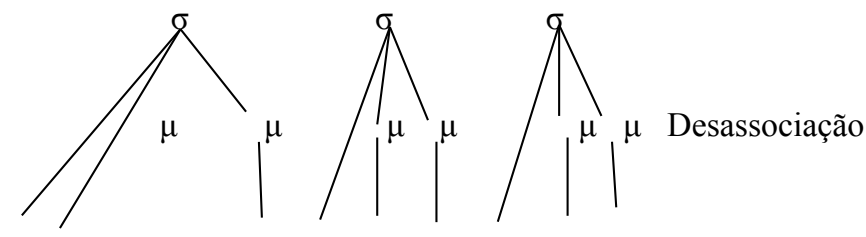

$\begin{array}{lllllllllllllllll}\mathrm{a} & \mathrm{k} & \mathrm{u} & \mathrm{i} & \mathrm{d} & \mathrm{u} & \mathrm{k} & \mathrm{t} & \mathrm{u} & \mathrm{s} & \text { mora }\end{array}$
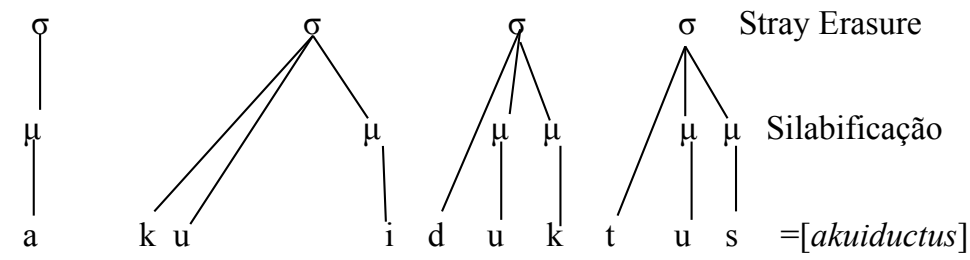

Em (24), a queda da vogal deixa a mora correspondente livre. Como a referida mora não é agregada a nenhum elemento, a mesma é elidida por Stray Erasure, resultando a variante monotongada.

A monotongação era tão comum em latim vulgar que os falantes, por vezes, aplicavam hipercorreção, como registra a sentença: "ac rustici pappum Mesium, non Maesium, a quo Lucilius scribit"9 (Os camponeses pronunciam Maesium e

9 VARRO, M. De língua latina. Liber VII. Disponível em: <http://www.thelatinlibrary.com/varro.II7.html>. Acesso em: 10 mar. 2010. 
não mesium, questão sobre a qual Lucílio escreveu). O exemplo maesium por mesium (meio) exemplifica o processo de hipercorreção encontrado na fala dos camponeses. Varro (96 a.C) registra outros casos desse tipo e Calabrese (2003) os utiliza como argumento para propor que a distinção qualitativa já estava presente em latim clássico.

De acordo com Calabrese (2003), não havia distinção quanto ao traço [ATR] dentre as vogais médias longas e curtas latinas, como por exemplo: caelum

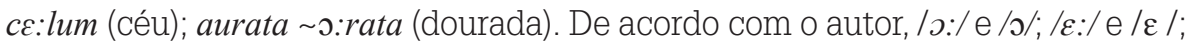
/e/ e /e:/; /o/ e /o:/ eram todas [-ATR] em latim clássico e, através de estágios, a diferenciação dentre as médias foi se implementando. Partindo desse e de outros pressupostos, quando a distintividade quantitativa se perdeu em latim vulgar, a distintividade qualitativa, que teria se desenvolvido desde o latim clássico, torna-se efetiva.

Formas dicionarizadas atestam que o ditongo latino fora substituído já em latim clássico: vaelius ou vēlus (velho); paene ou pēne (quase), ou seja, vaelius ve:lius; paene pe:ne. Esses dados corroboram a ideia de Calabrese (2003) e demonstram que a substituição era inerente ao sistema do latim clássico. Os estágios subseqüentes dessa mudança consistem na atribuição de valores diferentes de [ATR] para as médias longas e curtas e a perda da quantidade, resultando no sistema vocálico do latim tardio ou romance.

O latim vulgar também conserva mora da estrutura latina clássica, tal conservação se refletirá no comportamento da língua portuguesa. Na sentença n 85 do Glossário do Probo há um exemplo comumente citado por estudos mais tradicionais como alvo do fenômeno de vocalização em latim vulgar: pegma non peuma (tablado), que transforma uma consoante em vogal.

Podemos inferir, através do dado do Appendix Probi, que há conservação da mora via ditongação em latim vulgar. O segmento consonantal dorsal perdeu o ponto de consoante e um segmento vocálico, também dorsal, ocupou a mora flutuante. Dessa maneira, a mora é conservada. Veremos, mais adiante no trabalho, que essa opção disponível em latim vulgar é utilizada pelo português e que, assim como o latim vulgar, a língua portuguesa prima pela conservação da mora via ditongação.

O português, língua advinda do sistema qualitativo itálico ou vulgar, tem de lidar com os efeitos do fim da quantidade fonológica distintiva do sistema vocálico latino. Interessa-nos, também, explicar de que maneira a língua portuguesa resolve as consoantes geminadas. Ambas as questões estão inter-relacionadas com a estrutura moraica do latim ao português.

Como as vogais longas latinas já haviam se simplificado em latim tardio e início do romance, as mesmas não alcançaram as línguas românicas. Porém, os 
efeitos dessa simplificação afetaram as línguas. Vejamos como o português trata a simplificação da vogal longa latina.

(25) Perda de mora

\begin{tabular}{|c|c|}
\hline Latim & Português \\
\hline sūcu & Suco \\
\hline brūtu & Bruto \\
\hline tōtu & Tudo \\
\hline
\end{tabular}

O português não conserva a mora da vogal longa latina. Portanto, não há, nesses casos, manutenção da mora, como vemos em (26).

(26) Forma clássica [bru:tu] (bruto)
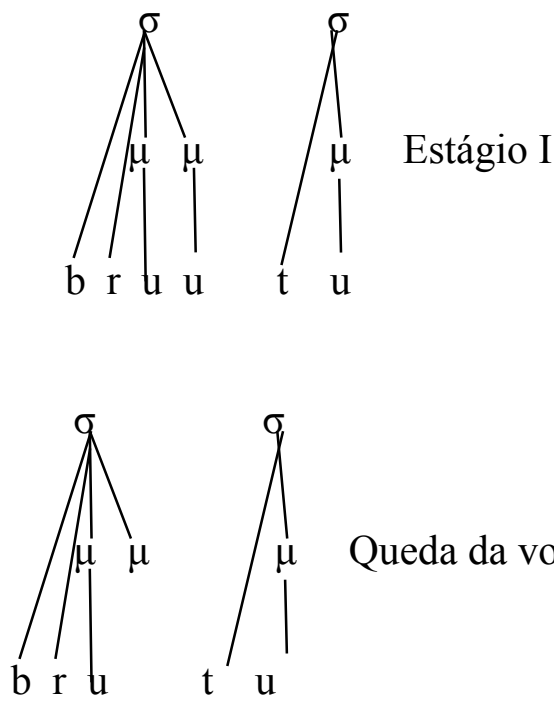

Queda da vogal

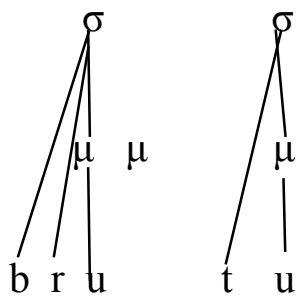

Desassociação da mora 

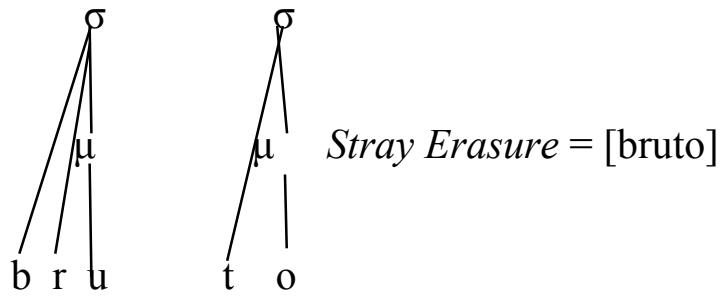

Em (26), ocorre a queda da vogal com consequente desassociação da mora que permanece flutuante e, por não ser reassociada, é elidida por Stray Erasure, resultando [bruto] em português, sem alongamento compensatório. As sequências - ct- e -pt- também não dão margem a geminadas na passagem ao português, mas simplificam-se, como vemos em (27).

(27) Perda de mora

\begin{tabular}{|c|c|}
\hline latim & Português \\
\hline corrēc\#to & Corrigido \\
\hline lecc\#to & Lido \\
\hline scrīp\#to & Escrito \\
\hline
\end{tabular}

Como o português não conserva a mora da vogal longa latina, o exemplo (28) mostra o processo de perda vocálica com consequente desassociação e elisão por Stray Erasure. É importante relembrar que o que nos interessa é a vogal longa, a consoante em questão é agregada à sílaba pela Regra de Adjunção de Segmentos restantes, sem portar mora.

(28) Forma clássica [lekto] (lido)

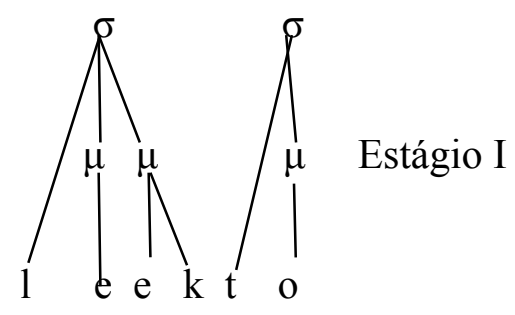




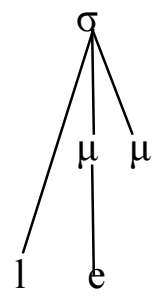

\section{Desassociação da mora}

\section{Queda da vogal e da consoante pós-vocálica}
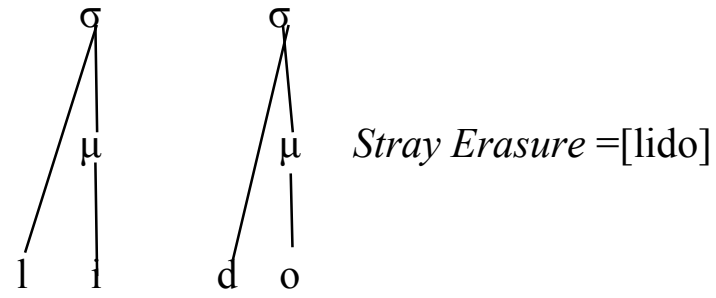

No entanto, a perda de mora não é uma regra geral, pois há casos nos quais a ditongação se aplica em palavras com encontros -ct-, como noctem>noite, em que a estrutura moraica do latim tem seu efeito, isto é, a mora da consoante é conservada, exemplos em (29).

(29) Conservação de mora

\begin{tabular}{|c|c|}
\hline latim & Português \\
\hline fac\#to & Feito \\
\hline noctem & Noite \\
\hline pectus & Peito \\
\hline regnum & Reino \\
\hline
\end{tabular}

As formas em (30) făctum, pěctus, lăctem, nŏctem, rĕgnum passam ao português como "feito, peito, leite, noite, reino". A diferença entre os dados em (27) e os dados em (29) reside no fato de que, em (29), a consoante pós-vocálica possui mora atribuída por Weigth by Position. Nesses casos, o português segue a escolha do latim vulgar e preserva a mora da consoante elidida via ditongação, exemplo (30). 
(30) [noktem] (noite)
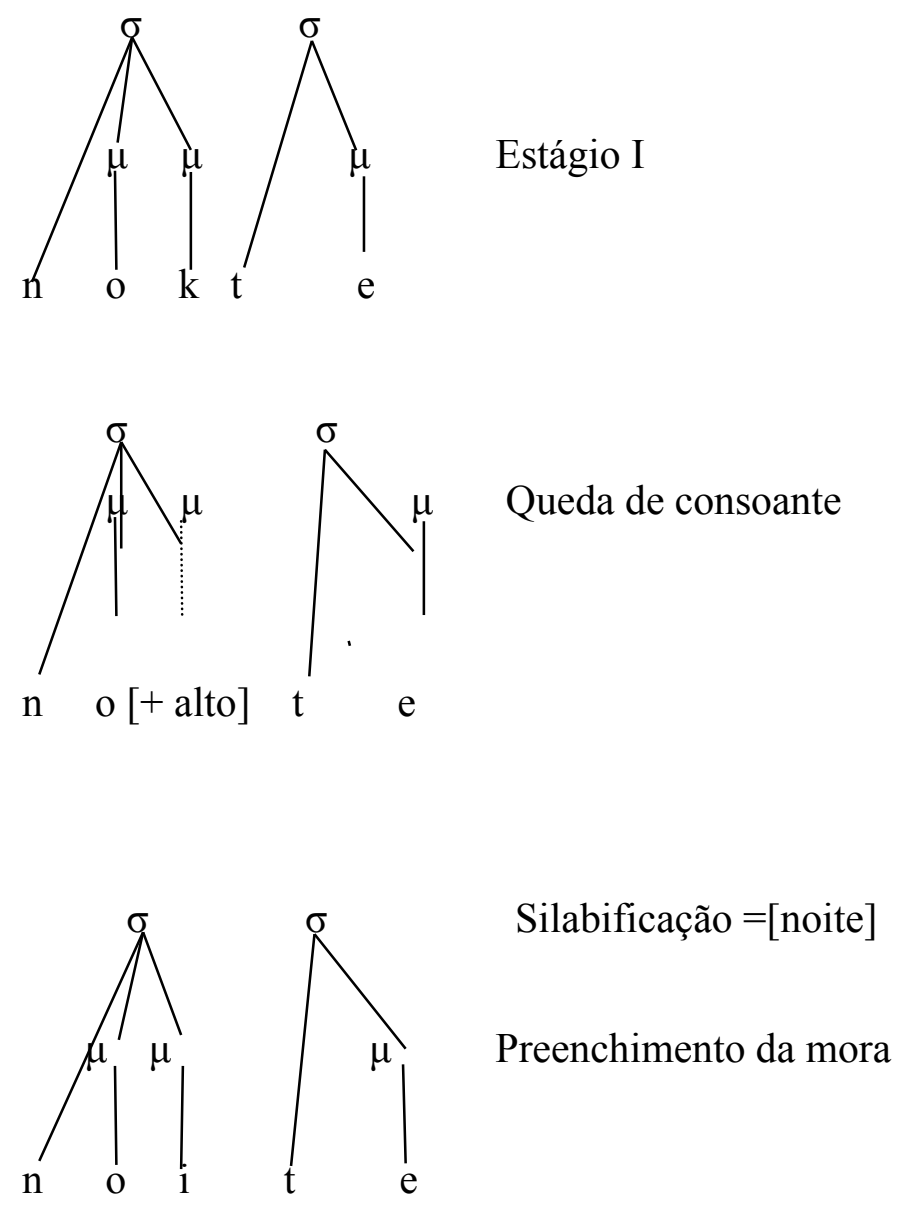

A consoante perdida, que é uma dorsal ou velar, caracteriza-se por possuir o traço [+alto], que é preservado quando de sua elisão. Essa posição é preenchida pelos traços correspondentes a uma vogal alta, preservando a mora através da criação de um ditongo decrescente, contribuindo para a manutenção da sílaba bimoraica.

O português só conserva a mora vocálica latina através do alongamento compensatório flop. O alongamento flop ocorre quando um elemento troca de sílaba e preenche uma posição moraica vazia, mantendo a sílaba bimoraica, exemplo (31). 
(31) [flo:rem] (flor)

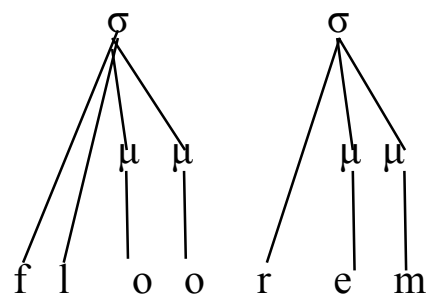

\section{Estágio I}
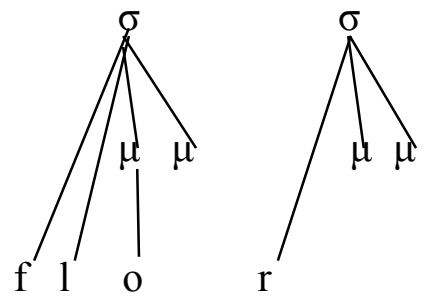

Queda das vogais e da consoante final
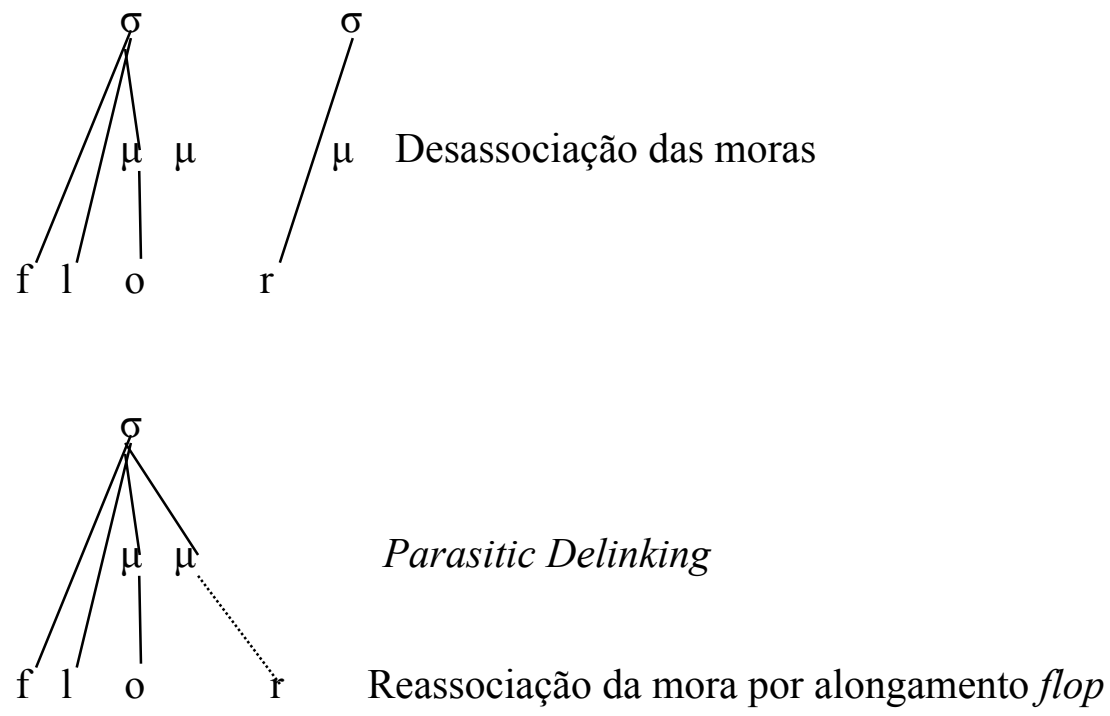

Silabificação $=[$ flor $]$ 
Em (31), temos Parasitic Delinking atuando ao desfazer a segunda sílaba sem núcleo. Como consequência, o alongamento flop reassocia o segmento ao preencher a posição moraica. Essa análise estende-se a dados nos quais há apagamento de consoantes intervocálicas do latim ao português: colorem, dolorem, amorem. A sílaba resultante é bimoraica.

No que se refere aos ditongos, o latim clássico dispunha de três: ae (caelum); oe (prosopopeia); au (tesaurus), dos quais apenas au passou ao português. Os demais

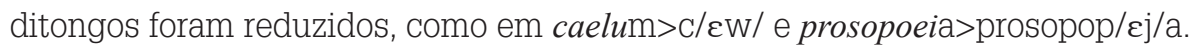
O português herda o ditongo au, como em aurum > ouro oro; tesaurus >tesouro oro. Variação semelhante ocorre em latim vulgar, ou seja, ambas as línguas optam pela perda da mora do ditongo. Segundo Bisol (1989), o ditongo ou, em português, está em processo de reanálise, ou seja, está sendo substituído por /o/ em qualquer contexto. Em suma, o português preserva a estrutura moraica latina em duas situações: (i) mora da consoante pós-vocálica; (ii) mora vocálica via alongamento flop, quando da atuação de Parasitic Delinking. As demais estruturas não têm efeito na língua portuguesa.

\section{Conclusões}

O modelo da Fonologia das Moras mostrou-se eficaz para descrever a estrutura do latim clássico e de sua variação em latim vulgar, bem como os efeitos dessas estruturas na passagem para o português: conservação ou perda de mora. O modelo, desenvolvido para estudos sincrônicos, consegue dar conta satisfatoriamente de fenômenos diacrônicos, proporcionando, sobretudo, analisar vários fenômenos como um único processo, ou seja, como mudança de estrutura moraica do latim e seus efeitos em português, utilizando apenas um modelo.

O português não conserva a mora das consoantes geminadas, como não conserva a mora das vogais longas. No entanto preserva a mora da consoante pós-vocálica (pectus>peito) e do ditongo latino (aurum>ouro), embora o referido ditongo esteja, em nossos dias, em processo de simplificação por reanálise. A mora da vogal longa é mantida em uma situação específica: alongamento flop engatilhado pela atuação de Parasitic Delinking. Stray Erasure, que atua elidindo moras não reassociadas, tem importante papel na evolução do latim ao português. Ambos os princípios aqui apontados atuam para satisfazer o Licenciamento Prosódico.

Espera-se que este olhar de caráter diacrônico à luz de uma teoria moderna, destinada sobretudo a estudos sincrônicos, ofereça alguma contribuição para os estudos linguísticos que se desenvolvem nessa área. 
COSTA, E. P. F. S. Moraic estructure change from Latin to Portuguese. Alfa, Araraquara, v.55, n.2, p.573-599, 2011.

- ABSTRACT: This study aims at investigating the evolution of the moraic structure from Latin to Portuguese. Latin, which presents vocalic and consonantal quantitative distinction, has the following syllable patterns: (i) light syllable, which contains a single mora (e.le.men. tum); (ii) heavy syllable, which contains two moras (bul.ga); (iii) super heavy syllable, which contains three moras according to our argument (paul.lum). Diachronically, there is a loss of quantitative distinctive among the vowels. From Latin to neo-Romance languages the moraic structure has its effects. Based on such information and on Hayes' Moraic Theory (1989), we intend to investigate the effects of such change in both languages by analyzing related phonological processes, such as diphthongization and monophthongation. Moraic Theory allows us both to identify the way moraic structures are attributed to languages and to determine which principles operate in these languages. Hayes (1989) defines a mora as a weight unit at the prosodic tier and represents the contrast between long syllables and short syllables. Also, a mora counts as a phonological position (a long segment is represented as being doubly linked). We argue that the choices made by the Portuguese language to deal with moraic structure of Latin had already been available in vulgar Latin and, according to the choices made, principles such as Stray Erasure and Parasitic Delinking, which are related to Prosodic Licensing, acted in the aforementioned change.

- KEYWORDS: Linguistic change. Latin. Moraic structure. Mora. Portuguese.

\section{REFERÊNCIAS}

APPENDIX Probi. Disponível em: <http://www.orbilat.com/Languages/Latin_ Vulgar/Vocabulary/Appendix_Probi.html>. Acesso em: 10 fev. 2011.

ARVANITI, A. Cypriot greek and phonetics and phonology of geminates. In: INTERNATIONAL CONFERENCE OF MODERN GREEK DIALECTS AND LINGUISTIC THEORY, 1., 2001, Patras. Proceedings... Patras: University of Patras. p.19-29. Disponível em: <http://idiom.ucsd.edu/ arvaniti/Arvaniti.geminates_ Patras2001.pdf>. Acesso em: 14 mar. 2010.

BISOL, L. O acento e o pé binário. Cadernos de Estudos Linguísticos, Campinas, v.22, p.69-80, 1992.

O ditongo na perspectiva da fonologia atual. Delta, São Paulo, v.5, n.2, p.185-224, 1989.

BRENNAN, J. A weight problem: vowel length in Classical Latin. 2008. Disponível em:<https://files.nyu.edu/jrb399/public/documents/Brennan_06a_A\%20Weight. pdf >. Acesso em: 14 mar. 2011.

BROWN, J. C. Floating moras and features in southern Sierra Miwok. WORKSHOP ON AMERICAN INDIGENOUS LANGUAGES, 6., 2003, Santa Barbara. Proceedings... Santa Bárbara: UCLA, 2003. v.14. Disponível em: <http://www. linguistics.ucsb.edu/research/Brown_vol14.pdf>. Acesso em: 17 dez. 2010. 
CALABRESE, A. On the evolution of the high vowels of latin to romance. 2003.

Disponível em: <http://homepages.uconn.edu/ anc02008/Papers/On\%20the\%20 evolution\%20of\%20short\%20high\%20vowels\%20of\%20Latin\%20into\%20Romance. pdf $>$. Acesso em: 15 mar. 2010.

CHUNG, Y. Vowel shortening and evidence for moraic consonant: a case from kyumgsang dialect of korean. Studies in phonetics, phonology and morphology, Amherst, n.3. p.247-264, 1997.

COHN, A. Phonological structure and phonetic duration: the role of the mora. Working Papers of the Cornell Phonetics Laboratory, Ithaca, v.15, p.69-100, 2003.

COUTINHO, I. L. Gramática histórica. 4. ed. Rio de Janeiro: Acadêmica, 1958.

CURTIS, E. K. J. Geminate weigth: case studies and formal models. 2003. $355 f$. Dissertation (Doctor of Philosophy) - University of Washington, Washington, 2003. Disponível em: <http://scholar.googleusercontent.com/scholar?q=cache:rxF7_ OVnP1kJ:scholar.google.com/+emily+curtis+geminate+weigth\&hl=pt-BR\&as_ sdt=0,5>. Acesso em: 17 dez. 2010.

ELFNER, E. The mora in blackfoot. 2006. 145f. Thesis (Master of Arts) - University of Calgary, Alberta, 2006. Disponível em: <http://www.people.umass.edu/eelfner/ morablackfoot.pdf>. Acesso em: 16 dez. 2010

FARIA, E. Fonética histórica do Latim. Rio de Janeiro: Acadêmica, 1955.

GASIOROWSKI, P. Heavy consonants and compensatory lengthening. Studia Anglica Posnaniensia, Poznam, p.71-80, 1991-1993.

GORDON, M. Weight-by-Position adjunction and syllable structure. 1999. Disponível em: <http://www.linguistics.ucsb.edu/faculty/gordon/weightbypos. pdf $>$. Acesso em: 20 dez. 2010.

GORDON, M. et al. Vowel and consonant sonority and coda weigth: a crosslinguistic study. In: WEST CONFERENCE ON FORMAL LINGUISTIC, 26., 2008, Somerville. Proceedings... Somerville: Cascadilla Proceedings Project. Disponível em: <http://www.lingref.com/cpp/wccl/26/paper1674.pdf>. Acesso em: 29 nov. 2010

GORE, M. Phonological and phonetics views of vowel sequence timing. 2003 Disponível em: <http://ado.lib.kagoshima-u.ac.jp/bitstream/10232/855/1/ KJ00004239438.pdf>. Acesso em: 25 dez. 2010.

GOLDSMITH, J. The syllable. 2009. Disponível em: <http://hum.uchicago. edu/ jagoldsm//Papers/syllables.pdf>. Acesso em: 10 fev. 2011.

HAYES. B. Compensatory legthning in moraic phonology. Linguistic Inquiry, Cambridge, n.20, p.253-306, 1989. Disponível em: <http://www.linguistics.ucla. 
edu/people/hayes/Papers/HayesCompensatoryLengthening1989.pdf>. Acesso em: 24 set. 2010.

HAYES, B. Metrical stress theory: principles and case studies. Chicago: Chicago Press, 1995.

HAYES, B. et al. Explaining sonority projection effects. Phonology, Cambridge, n.28, p.197-234, 2011.

HARRIS. H. Syllable structure and stress in Spanish: a non-linear analysis. Cambridge: MIT Press, 1983.

HUME, E; MULLER, J; ENGELENHOVEN, A. Initial geminates in leti: consequences for moraic theory. Studies in the Linguistics Sciences, Urbana, v.27, n.1, Spring. 1997. Disponível em: <http://www.jstor.org/pss/4420109>. Acesso em: 15 dez. 2010.

KAVITSKAYA, D. Triggers and alternations in compensatory lengthening. In: WEST COST CONFERENCE OF FORMAL LINGUISTICS, 21., 2002, Somerville. Proceedings... Somerville: Cascadilla Press, 2002. p.101-114.

LAHIRI, A; RIAD, T; JACOBS, H. Diachronic prosody. 1999. Disponível em: <http:// www.ling-phil.ox.ac.uk/files/uploads/diachronic_prosody_lahiri_et_al.pdf>. Acesso em: 14 dez. 2010.

LAUSBERG. H. Linguística românica. Lisboa: Fundação Calouste Gulbenkian, 1963.

LEE, S. Síncope, Brevis Brevians e acento no português brasileiro. Letras de Hoje, Porto Alegre, v.38, n.4, p.163-176, 2003.

Morfologia e fonologia lexical do Português do Brasil. 201 f. Tese. (Doutorado em Linguística) - Instituto da Linguagem, Universidade Estadual de Campinas, Campinas, 1995.

LUNDEN, A. Weigth, final lengthening and stress: a phonetic and phonological case study of norwegian. 2006. $217 \mathrm{f}$. Thesis (Doctor of Philosophy and Linguistics) - University of California, Los Angeles, 2006. Disponível em: <http://roa.rutgers. edu/view.php3?id=1157> . Acesso em: 20 dez. 2010

MAGALHÃES, J. S. de. O plano multidimensional do acento na teoria da otimidade. 2004. 216f. Tese (Doutorado em Linguística Aplicada) - Faculdade de Letras, Pontifícia Universidade Católica do Rio Grande do Sul, 2004.

MASSINI-CAGLIARI, G. Do poético ao linguístico no ritmo dos trovadores: três momentos da história do acento. São Paulo: Cultura Acadêmica, 1999.

Cantigas de amigo: do ritmo poético ao linguístico. Um estudo do percurso histórico da acentuação em Português 1995. 300f. Tese (Doutorado 
em Linguística) -Instituto de Estudos da Linguagem, Universidade Estadual de Campinas, Campinas, 1995.

McCRAY, K. Syllable structure versus segmental phonotatics: geminates and clusters in italian revisited. 2006. Disponível em: <http://uts.cc.utexas. edu/ tls/2002tls/Kristie_McCrary.pdf>. Acesso em: 20 dez. 2010.

MORÉN, T. B. Distinctiveness, coercion and sonority. a unified theory of weight. 1999. 420f. Thesis (Doctor of Philosophy) - University of Maryland, College Park, 1999. Disponível em: <http://roa.rutgers.edu/files/346-0999/346-0999MOREN-0-0.PDF>. Acesso em: 15 mar. 2011.

ODDEN, D. The representation of vowel length. Disponível em: <http://www.ling. ohio-state.edu/ odden/>. Acesso em: 14 set. 2010.

ONZI, M. L. Consoantes geminadas em italiano: um estudo fonético/fonológico. 2007. 96f. Dissertação (Mestrado em Linguística) - Universidade Federal de Santa Catarina, Florianópolis, 2007.

OOSTENDORP, M. Mora theory. 2005. Disponível em: <http://www.vanoostendorp. nl/pdf/051122.pdf>. Acesso em: 14 set. 2010.

PULLEYBLANK, D. Underlying mora structure. Linguistic Inquiry, Cambridge, v.25, n.2, p.344-353, Spring. 1994.

RENZI, L. Introduccíon a la filologia românica. Madrid: Gredos, 1982.

ROSENTHALL, S.; VAN DER HULST, H. Weight-by-position by position. Natural Language and Linguistic Theory, Dordrecht, n.17, p.499-540, 1999. Disponível em: <http://www.linguistics.uconn.edu/pdf/091-WeightbyPosition.pdf>. Acesso em: 15 fev. 2011.

SHAW, J. Compensatory lengthening via mora preservation in OT-CC. Theory and predictions. 2008. Disponível em: <http://roa.rutgers.edu/files/916-0607/916SHAW-0-0.PDF>. Acesso em: 15 mar. 2010.

SILVA NETO. S. História do latim vulgar. Rio de Janeiro: Acadêmica, 1957.

VARRO, M. M. Terenti Varronis de Lingua Latina: Liber VII. Disponível em:<http:// www.thelatinlibrary.com/varro.II7.html>. Acesso em: 10 mar. 2010.

TORRINHA, F. Dicionário latino português. 7. ed. Porto: Gráficos Reunidos, [1942?].

Recebido em março de 2011.

Aprovado em julho de 2011 